\title{
MEDIA BOOKLET COMPANY PROFILE CV. SARY CARDS SAMARINDA PENUNJANG AKTIVITAS KOMUNIKASI PEMASARAN
}

\author{
Kezia Arum Sary ${ }^{1}$, Sarwo Eddy Wibowo ${ }^{2}$, Amar Makruf Jauhari ${ }^{3}$, Arfian Rony Ashadi ${ }^{4}$ \\ ${ }^{1,3,4}$ Program Studi Ilmu Komunikasi, Fakultas Ilmu Sosial dan Politik Universitas Mulawarman \\ Samarinda \\ ${ }^{2}$ Program Studi Manajemen, Fakultas Ekonomi Universitas 17 Agustus 1945 Samarinda \\ Email : kezia.arumsary@fisip.unmul.ac.id
}

\begin{abstract}
CV. Sary Cards, located in Samarinda, East Kalimantan, is an industry engaged in the printing and procurement of goods and services. Specific products that are the uniqueness or focus of this printing are in the form of invitations, be it wedding invitations, birthdays, building inaugurations, tasmiyah and so on. However, in today's all-digital era, the printing industry has to undergo many changes with many new competitions through the digital market. Not only changes in the way of selling, but the increasingly diverse products that have begun to shift with technological developments, as well as the way of production. The company profile booklet media is used as a marketing communication activity to be able to survive the competition in this digital era. The compilation of this profile booklet takes a practice-based approach with the communication planning model used is SOSTAC analysis and uses two types of data, primary and secondary.
\end{abstract}

Keywords: Media Booklet; Company Profile; Marketing Communication.

\section{Abstrak}

CV. Sary Cards yang berada di Samarinda, Kalimantan Timur ini merupakan industri yang bergerak di bidang percetakan dan pengadaan barang dan jasa. Produk spesifik yang menjadi kekhasan atau fokus dari percetakan ini yaitu berupa undangan, baik itu undangan pernikahan, ulang tahun, peresmian gedung, tasmiyah dan sebagainya. Namun pada era yang serba digital saat ini, industri percetakan harus mengalami banyak perubahan dengan banyaknya persaingan baru lewat pasar digital. Tidak hanya perubahan pada cara menjual, akan tetapi semakin beragamnya produk yang mulai bergeser dengan adanya perkembangan teknologi, juga terhadap cara berproduksinya. Media booklet company profile digunakan sebagai aktivitas komunikasi pemasaran untuk mampu bertahan menghadapi persaingan era digital ini. Penyusunan booklet company profile ini melakukan pendekatan berbasis praktik (practice based research) dengan model perencanaan komunikasi yang digunakan adalah analisis SOSTAC dan menggunakan dua jenis data, primer dan sekunder.

Kata kunci: Media Booklet; Company Profile; Komunikasi Pemasaran.

\section{PENDAHULUAN}

Aktivitas komunikasi pemasaran menjadi upaya yang penting dilakukan bagi sebuah perusahaan untuk memperkenalkan produk atau jasa yang dikelolanya (Tjiptono, dalam Wibowo, 2017), bahkan sebagai cerminan identitas perusahan tersebut. Sehingga perancangannya pun hendaknya dilakukan dengan perencanaan yang matang. Diperlukan pemahaman yang detail terkait visi dan misi perusahaan yang berisi rencana yang akan dilakukan di masa yang akan datang 
(Hamdan, 2001), target perusahaan, dan kondisi perusahaan untuk merancang aktivitas komunikasi pemasaran yang efektif sesuai dengan harapan perusahaan dan mampu diterima oleh masyarakat (Jayadi, 2016), terlebih dalam era digitalisasi saat ini.

Era digitalisasi yang kita hadapi saat ini memudahkan berbagai usaha untuk melakukan pengembangan usaha dan menjual hasil usahanya (Prihadi, 2017). Akan tetapi, era digitalisasi ini pula dapat menggerus omset pelaku usaha industri grafika. Oleh karena itu, para pelaku usaha harus jeli dalam melihat kebutuhan pasar agar mampu bertahan dan bersaing.

Tidak hanya itu, era digitalisasi menjadikan persaingan tak hanya terjadi pada pasar dalam negeri, tapi juga berasal dari pasar mancanegara. Para pelaku usaha industri grafika Indonesia juga harus kompak dan saling bersinergi agar tidak menjadi penonton saja dalam persaingan ini. Seperti pemaparan Ahmad Mughira Nurhani, Ketua Umum Persatuan Perusahaan Grafika Indonesia sebagai berikut: "Pesaing usaha ini, tidak hanya domestik namun juga ada dari luar negeri . Kita harus bersiap, jangan sampai menjadi penonton, atau calo saja. Ini hanya bisa dilawan percetakan Indonesia, dengan harus kompak, tidak saling sikut, tidak saling banting-bantingan harga,"

Dalam menghadapi persaingan ini, mengharuskan sebuah perusahaan untuk merencanakan media komunikasi seperti apa yang akan digunakan untuk menjangkau pasar dan membuat diferensiasi dengan para pesaing karena konsumen menyukai sesuatu yang "berbeda" (Ferdinand, 2017). Salah satu media komunikasi yang dapat digunakan adalah booklet. Booklet berisi informasi mengenai produk, layanan, fasilitas hingga profil suatu perusahaan. Booklet ini juga dimanfaatkan sebagai sarana pemasaran atau beriklan (Putra, 2016). Sebagai salah satu perusahaan yang bergerak di bidang percetakan, CV. Sary Cards menggunakan media booklet company profile untuk menjangkau pasar dan berhubungan dengan konsumen. Penelitian ini bertujuan untuk mengkaji bagaimana proses pembuatan media booklet company profile oleh CV.Sary Cards dalam persaingan pada era digitalisasi ini.

Company profile atau profil perusahaan merupakan media yang merepresentasikan perusahaan (organisasi) yang berisikan gambaran umum perusahaan. Tujuan utama dibuatnya company profile adalah memperkenalkan kepada khalayak informasi tentang perusahaan tersebut berkaitan dengan nama perusahaan, tagline, logo, sejarah serta rencana untuk masa yang akan datang (Iman, 2016). Company profile dikemas untuk memperkenalkan produk secara verbal maupun grafik yang mengangkat corporate value serta product value juga keunggulan perusahaan dibandingkan kompetitor berdasarkan kedua value.

Menurut Kriyantono (2008) gambaran dalam company profile tidak sepenuhnya lengkap detail dan mendalam, perusahaan dapat memilih poin-poin apa saja yang akan disampaikan secara terbuka kepada publiknya. Bahkan ada perusahaan yang hanya membuat company profile berdasarkan kebutuhan publik sasaran. Sehingga tujuan utama dalam perancangan company profile adalah mendekatkan perusahaan dengan lingkup target pasar baru yang penting dalam pertumbuhan bisnis perusahaan tersebut. Hal ini diarahkan kepada investor potensial maupun diarahkan kepada konsumen baru untuk memperlebar bisnis atau mencari 
sumber daya baru baik sumber daya alam maupun sumber daya manusia yang berkualitas yang mampu membantu pertumbuhan perusahaan.

\section{METODE}

Pendekatan penelitian yang digunakan yaitu kualitatif dengan pendekatan berbasis praktik (practice based research) untuk upaya memecahkan masalah dan mencapai tujuan pembuatan media komunikasi pemasaran, sehingga membutuhkan proses pengumpulan data. Model perencanaan komunikasi yang digunakan adalah analisis SOSTAC, menurut Smith (1998), terdapat 6 tahapan dalam analisis SOSTAC ini, yaitu situasi (situation), tujuan (objective), strategi (strategy), taktik (tactics), aksi (actions), kendali (control). Data yang digunakan yaitu dengan pengumpulan data langsung tentang CV. Sary Cards, setelah semua data terkumpul kemudian dilakukan analisis untuk mendapatkan informasi yang perlu dikembangkan pada konsep media komunikasi pemasaran berupa booklet company profile bagi CV. Sary Cards dengan teknik pengumpulan data melalui observasi, wawancara, dokumentasi, dan studi literatur.

\section{HASIL DAN PEMBAHASAN}

CV. Sary Cards, merupakan sebuah perusahaan yang bergerak di bidang percetakan dan pengadaan barang dan jasa. Di bawah bimbingan Suharno perusahaan ini berlokasi di Jalan Pramuka 8 No. 2 Samarinda, dan saat ini telah membuka cabang di Jalan MT. Haryono N0. 107 Samarinda. Pada bulan Mei 1995 perusahaan ini hanya dimulai dengan proses cetak sederhana berupa sablon dan terbatas pada mencetak undangan-undangan, khususnya undangan pernikahan (wedding cards). Sebetulnya, usaha ini tercipta dari adanya perkembangan bisnis keluarga. Belajar dari pengalaman dan adanya peluang terhadap kebutuhan pasar maka diambillah keputusan untuk membuka usaha sendiri (home industry) bersama keluarga intinya, yaitu istri, anak dan adik-adik ipar dari Suharno.

Bagi Suharno memulai usaha kecil bersama keluarga bisa menjadi tantangan yang unik. Selain itu akan sangat membantu dalam urusan kepercayaan dan cara yang bagus untuk mengajak semua anggota keluarga untuk bersama-sama demi menjaga keamanan generasi selanjutnya. Suharno menanamkan suatu keyakinan dalam dirinya, bahwa apa yang ia tumbuhkan sebagai sebuah usaha kecil di bidang percetakan undangan pernikahan (wedding cards), pada saatnya yang tepat akan menjadi sebuah andalan di sektornya. Perusahaan terus mengalami improvisasi yang cukup signifikan secara internal dan eksternal baik perubahan struktur dan "rebranding", searah dengan perkembangan zaman teknologi dan kompetisi bisnis di Indonesia.

Pada sebuah perusahaan, company profile adalah media penting dalam menunjang aktivitas komunikasi pemasaran, menjadi kekuatan dalam membangun citra perusahan di mata relasi dan mitra kerja. Company profile memuat deskripsi singkat mengenai sejarah perusahaan, latar belakang perusahaan secara keseluruhan, asetaset perusahaan, visi-misi perusahaan dan reputasinya, struktur organisasi dan manajemen, alur kerja perusahaan secara keseluruhan, produk dan nilai perusahaan, serta penghargaannya (Narolita, 2012). Booklet company profile dimanfaatkan sebagai salah satu identitas atau tanda pengenal suatu organisasi maupun perusahaan yang 
dikemas dalam bentuk sebuah buku (Maimunah, 2012).

Bagi sebuah perusahaan company profile memiliki peranan yang cukup penting dalam menjalankan business to business, karena mampu merepresentasikan visi misi perusahaan atau menyampaikan produk yang akan ditawarkan kepada calon konsumen, baik itu perusahaan, lembaga ataupun instansi terkait lainnya (Sunarya, 2013). Selain itu merupakan alat komunikasi pemasaran yang efektif, karena memanfaatkan unsur visual berupa gambar dan teks.

Tabel 1. Matrik Kekuatan, Kelemahan, Peluang, dan Ancaman

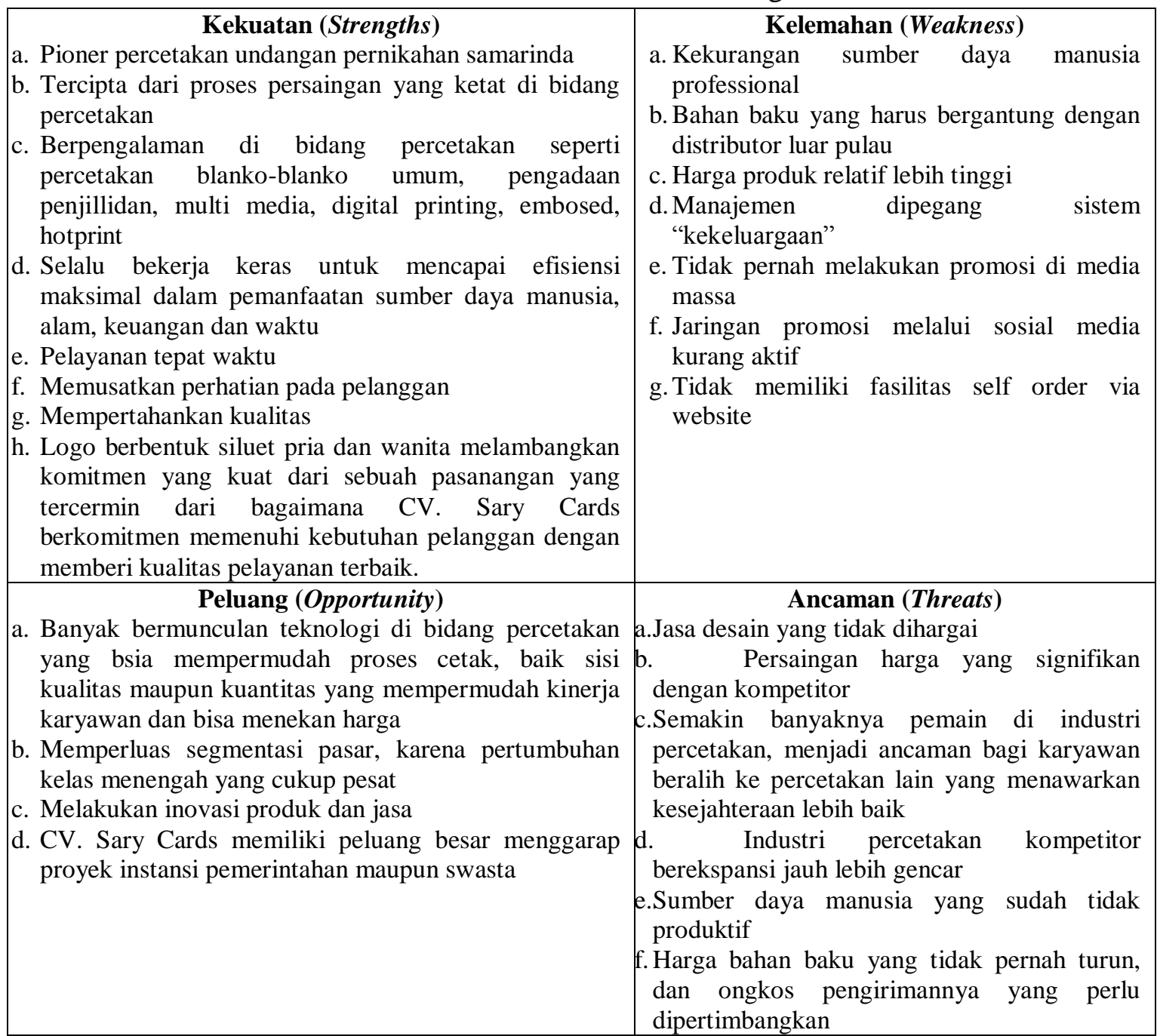

Sumber: Hasil penelitian, 2020.

\section{Segmentasi dan Positioning}

Langkah-langkah perancangan media booklet company profile diperlukan penyusunan strategi kreatif dengan menentukan target market yang merupakan pengguna dari produk atau jasa khususnya demografi dan geografis, selain itu target audiens yang merupakan faktor pengaruh dijabarkan dengan data psikografi. Target market, dibedakan menjadi segmen demografi (jenis kelamin laki-laki dan perempuan; status ekonomi kelas menengah atas; segmen geografis wilayah Kalimantan 
Timur. Target audiens dari segmen psikografi adalah dari semua kalangan pendidikan, semua jenis pekerjaan khususnya lembaga, perusahaan atau instansi yang membutuhkan jasa percetakan dan pengadaan barang dan jasa.

\section{Strategi Kreatif}

Booklet Company Profile CV. Sary Cards Samarinda adalah sejenis media promosi yang di dalamnya terkandung informasi-informasi tentang sejarah, visi misi, lokasi serta alur kerja produksi hingga hasil produksi. Booklet ini dibuat menggunakan aplikasi CorelDraw dengan 12 halaman dan dicetak dalam kertas Art Paper 260gram untuk cover dan Art Paper 150 gram untuk isi booklet dengan ukuran $21 \mathrm{~cm} \mathrm{x}$ $29.7 \mathrm{~cm}$. Booklet dibuat dengan mengambil tema simple elegan menyesuaikan produk, karakter perusahaan dan berdasarkan model SOSTAC. Untuk publikasi booklet dibuat secara tercetak maupun dibagikan kepada pihak instansi pemerintah maupun swasta sebagai media promosi terobosan terbaru.

Strategi visual kreatifitas sangat melekat dalam dunia desain grafis, karena dibutuhkan dalam menghasilkan konsep-konsep yang tidak monoton. Dalam konsep kreatif dibutuhkan rancangan yang matang dalam hal gaya desain dan apa saja yang akan disampaikan kepada target audiens sehingga menghasilkan karya yang mampu mengkomunikasikan pesan secara tepat dan mampu membedakannya dengan pesaing dalam kategori serupa (Suyanto, dalam Handayani, 2015). Dua bentuk pesan yang dikemas dalam company profile yaitu :

\section{Visual Verbal}

Terdiri dari judul atau headline merupakan fokus utama dari pesan yang ingin disampaiakan berupa kalimat persuasif, teks isi atau body copy yang jelas dan singkat sehingga mudah dimengerti oleh target audiens. Unsur-unsur dalam naskah terdiri dari judul, sub judul, teks isi, dan tagline

2. Visual Non-Verbal

Sebagai pendukung pesan melalui ilustrasi berupa foto dokumentasi untuk memperjelas teks ataupun pesan serta sebagai daya tarik. Penggunaan tipografi sesuai dengan tema dan sifat pesan yang disampaikan, pemilihan warna juga disesuaikan dengan identitas perusahaan dan mempertimbangkan kenyamanan, juga membuat layout yang menarik dan mudah dipahami dengan baik.

a. Ilustrasi

Pada booklet ini menyajikan ilustrasi berupa foto atau dokumentasi perusahaan mengenai produk-produk yang telah dihasilkan, selain itu terdapat ilustrasi berupa gedung atau industri, mesin, para karyawan dan juga hal-hal yang berkaitan dengan percetakan.

b. Tipografi

Tipografi yang digunakan mempertimbangkan keterbacaan dan kemenarikan serta huruf tertentu yang dapat membangun citra perusahaan. Pemilihan dan penggunaan jenis huruf disesuaikan dengan tema dan sifat dari pesan sehingga dapat menarik perhatian, mudah dibaca dan diingat, serta tidak tenggelam dalam ilustrasi. Dalam perancangan ini dipilih jenis huruf sans serif yaitu yang memberi kesan dinamis dan modern. Selain itu menggunakan huruf serif, pemilihan huruf ini mirip dengan huruf pada logo 
CV. Sary Cards sebagai ciri khas dari perusahaan yang memiliki kesan intelektual. Huruf ini memiliki kait dengan ketebalan kontras yang merupakan jenis huruf formal.

c. Warna

Warna memiliki kekuatan dalam mempengaruhi citra ketika khalayak melihatnya. Pemilihan warna disesuaikan dengan tujuan, tema dan latar belakang target audiens selain itu dapat mencerminkan karakter dan image perusahaan. Pada perancangan ini menggunakan warna hijau merupakan lambang kehaarmonian, mewakili kemakmuran. Pemilihan warna diatas sesuai dengan CV. Sary Cards sehingga dapat menjadi daya tarik dan pembeda dengan perusahaan lain.

d. Layout

Layout merupakan gaya menyusun dan mengatur teks atau grafik pada halaman, dengan tujuan membantu pembaca untuk memahami informasi sehingga menyusun layout harus memperhatikan karakter perusahaan dengan media yang digunakan serta target audiens yang dituju. Dalam perancangan ini digunakan bentuk potrait yang masing-masing bidangnya sejajar dengan bidang penyajian gambar dan tulisan yang saling berpadu saling melengkapi informasi sehingga membentuk suatu komposisi yang konseptual dan menambah elemen-elemen yang menarik.

\section{Gambar 1. Media Booklet Company \\ Profile CV. Sary Cards Samarinda}

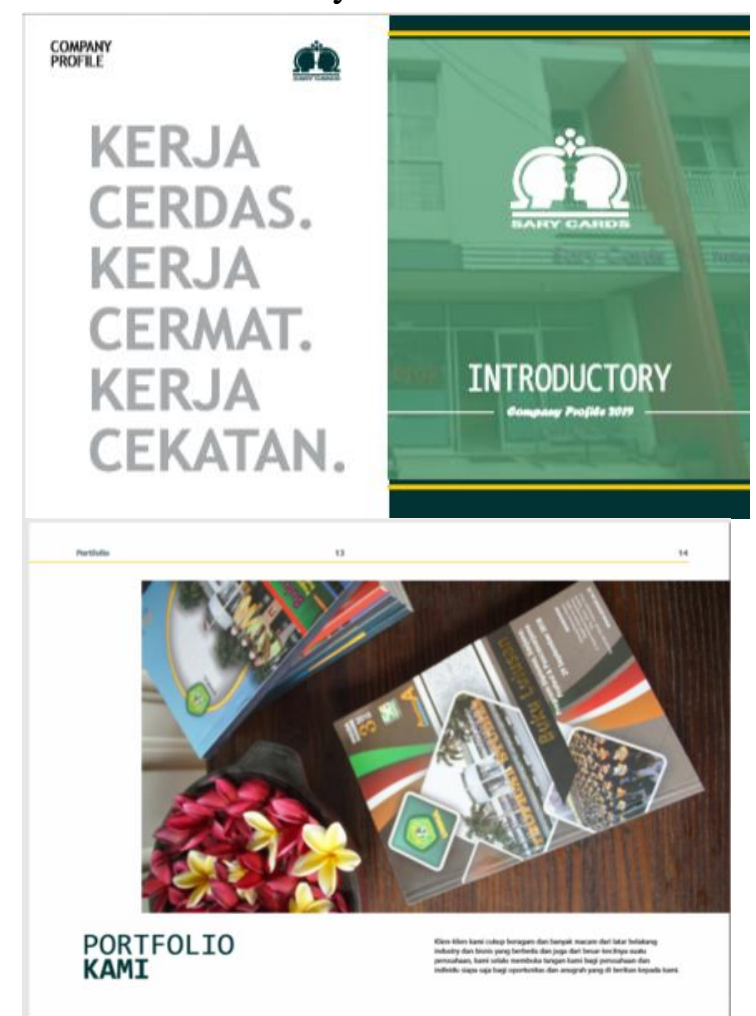

Sumber: Hasil penelitian, 2020.

\section{PENUTUP}

Sebagai perusahaan yang bergerak di bidang industri percetakan, CV. Sary Cards termasuk salah satu perusahaan yang maju dan mampu bertahan di Samarinda. Namun seiring dengan perkembangan era digitalisasi dan dikarenakan banyaknya kompetitor yang muncul, diperlukan suatu promosi yang kuat untuk memenangkan persaingan. Kemudian selain itu keadaan target audience-nya pun sudah berubah seiring dengan perkembangan jaman yang ada. Demi mempertahankan nama CV. Sary Cards, maka dibuatlah konsep dan kegiatan promosi baru yang lebih memfokuskan dan bertujuan kepada klien dan untuk mendapatkan awareness dari target audience. Konsep yang baru ini dapat membuat CV. Sary Cards memperluas jangkauan target audience di seluruh wilayah Samarinda 
bahkan hingga Kalimantan Timur. Konsep CV. Sary Cards ini adalah perusahaan ingin mengenalkan perusahaan mereka sebagai perusahaan yang bergerak di bidang industry percetakan yang memiliki tema yang handal dan berkualitas. Ditinjau dari segi pesannya, pesan komunikasi yang ingin disampaikan adalah dalam betuk sederhana dan jelas mengikuti perkembangan jaman sekarang. Oleh karena itu, tema dan gaya visualisasi yang akan digunakan adalah tema dan gaya simpel, profesionalitas, formal dan berkonsep sehingga dapat menarik awareness dari target audience.

\section{DAFTAR PUSTAKA}

Ferdinand, A. (2017). Keunggulan Diferensiasif dan Kinerja Pemasaran, Jurnal Bisnis Strategi, 12(8). pp. 1-18, Apr. 2017. https://doi.org/10.14710/jbs.12.8.1 $-18$

Hamdan, Y. (2001). Pernyataan Visi dan Misi Perguruan Tinggi. Jurnal Mimbar, 17(1).

Handayani, D.N., et al. (2015). Analisis Isi Visual Iklan dan Strategi Kreatif Kategori Print Ad Pemenang Gold, Silver, dan Bronze Citra Pariwara 2015. Jurnal Makna Volume, 6(1).

Iman, N. (2016). Efektivitas Penggunaan Company Profile dalam Membentuk Citra Positif Perusahaan Pertamina. Skripsi. Medan: Fakultas Ilmu Sosial dan Ilmu Politik Universitas Muhammadiyah Sumatera Utara.

Jayadi, I. (2016). Perancangan Media Promosi Dalam Bentuk Booklet Sebagai Sarana Iklan Media Cetak Produk Terhadap Tingkat Ketertarikan Pelanggan Pada PT. Prima Mitra Setia Sejati. Jakarta:
Institut Bisnis dan Multimedia ASMI.

Kriyantono, R. (2008). Public Relations Writing: Media Public Relations Membangun Citra Korporat. Jakarta : Kencana Prenada Media Group.

Maimunah., dkk. (2012). Media Company Profile sebagai Sarana Penunjang Informasi dan Promosi. Jurnal Eksplora Informatika, 5(3).

Narolita, M. (2012). Genre Analysis on Company Profile. Lantern (Journal on English Language, Culture and Literature), 1(2).

Prihadi, S.D. (2017). Industri Printing Memasuki Era Digital 4.0. Diakses pada 9 November 2020, dari

https://www.cnnindonesia.com/te knologi/20170422073622-185-

209408/industri-printingmemasuki-era-digital-40.

Putra, Y.O. (2016). Perancangan Komunikasi Visual Booklet Promosi Pariwisata Danau Kembar Alahan Panjang. Jurnal DEKAVE, 4(2).

Smith, P.R. (1998). Marketing Communications: An Integrated Approach. 2 nd Ed. London: Kogan Page.

Sunarya, L., dkk. (2013). Enriching Company Profile sebagai Penunjang Media Informasi dan Promosi pada Perguruan Tinggi Raharja. Jurnal Eksplora Informatika, 7(1).

Wibowo, A. L \& Priansa, D.J. (2017). Manajemen Komunikasi dan Pemasaran. Bandung: Alfabeta. 